\title{
Educación formal/educación popular: Dinámicas de adaptación y resistencia a la modernidad. Experiencia recorrida en la provincia de Guanacaste, Costa Rica (2012-2013)
} Formal education/popular education: dynamics regarding adaptation and resistance to
modernity. Experience studied in the province of Guanacaste, Costa Rica (2012-2013)

\author{
Ernesto Herra Castro \\ Universidad Nacional. Costa Rica. ernesto.herra.castro@una.cr
}

Fecha de recepción: 1/12/2014. Reenvios: 5/11/2015 - 9/5/2016.

Fecha de aceptación: 20/5/2016. Fecha de publicación: 13/06/2016.

\begin{abstract}
Resumen: Discute respecto de la lógica y el orden vertical de dominio contenido en la modernidad y de su expresión concreta en la dinámica educativa costarricense. Muestra la tensión existente entre educación formal y las posibilidades de libertad y desconexión al orden impuesto en la modernidad que busca y propicia la educación popular. Lo anterior se hace con base en la experiencia del proyecto "Alfabetización crítica en la cultura escolar: Sociedad y Derechos Humanos" en la provincia de Guanacaste.
\end{abstract}

Palabras claves: Costa Rica, Guanacaste, educación, modernidad, colonialidad, extracción minera, exclusión educativa.

\begin{abstract}
The author discusses the logic and the domain's vertical order in modernity, as well as its concrete expression in the Costa Rican educational dynamics. The paper shows the existing tension between formal education and the possible freedom and detachment from the imposed order in modernity pursued and promoted by popular education. This is done based on the project entitled "Critical Literacy in School Culture: Society and Human Rights" executed in Guanacaste.
\end{abstract}

Keywords: Costa Rica, Guanacaste, Education, Modernity, Coloniality, Mineral Extraction, Educational Exclusion.

\section{Introducción}

Durante el mes de enero de 2012 y el mes de diciembre 2013 se ejecutó la segunda fase de "Alfabetización crítica en la cultura escolar: Sociedad y derechos humanos", proyecto de investigación, extensión y docencia integrado por la División de Educología y la Escuela de Sociología de la Universidad Nacional, en la cual se acompañaron distintas experiencias de 
educación popular en la provincia de Guanacaste. En esta fase se tuvo la oportunidad de ampliar el ámbito de acción e impulsar la discusión en zonas urbanas y rurales, lo que permitió establecer balances y acercamientos diversos respecto de las formas de problematizar y enfrentar realidades sociales diversas a través de prácticas educativas.

El presente documento se deriva de tal investigación e intenta dar a conocer las principales líneas de discusión, problematización y acción en el campo de la educación popular en contextos comunitarios rurales costarricenses.

Si bien la experiencia en la que se basa parte de la vivencia de la comunidad de Corral de Piedra, Nicoya, Guanacaste, me atrevo a soñar que este tipo de prácticas están presentes en una parte importante de las comunidades rurales costarricenses donde, para hacer posible la vida, es necesario crear vínculos con la educación.

\section{Encuentros, desencuentros y salvedades metodológicas de partida con miras a la trans- formación comunitaria y popular}

La vinculación del proyecto ejecutado por la División de Educología y la Escuela de Sociología de la Universidad Nacional, denominado "Alfabetización crítica en la cultura escolar: Sociedad y derechos humanos", ejecutado ente los meses de enero (2012) y diciembre (2013), en diversas comunidades guanacastecas, se dio como una acción coherente ante el tipo de metodología (investigación acción participativa) de la que este proyecto parte.

En su inicio, se pensó en la posibilidad de que esta segunda fase del proyecto, que ya de por sí pensaba críticamente el fenómeno educativo, pudiese llegar a las comunidades de León Cortés y San Marcos de Tarrazú, ambas en las zona de "Los Santos", delimitadas a partir de un ejercicio investigativo anterior, como la zona de nuestro país donde la exclusión educativa se muestra con mayor severidad (Herra, 2008, 2012). Aun cuando el equipo contaba con información cuantitativa que dejaba evidencia de que Tarrazú era el cantón, a nivel nacional, con mayor índice de exclusión de jóvenes, entre los 12 y 17 años de edad, del sistema educativo formal (Herra, 2008), este fenómeno no era percibido por la población como un problema social que le afectara y esto, principalmente, porque Tarrazú, Pérez Zeledón, Valverde Vega, León Cortés y Dota son los cinco cantones con mayor porcentaje de migración en el territorio nacional (Acuña, 2015). Debido a que el 65\% de migrantes costarricenses radica en los Estados Unidos (Acuña, 2015); a que la población de jóvenes expulsados del sistema educativo formal en la zona de los Santos veía su futuro en ese país (Herra, 2008); y a que la educación formal costarricense no le aportaba nada para sus propósitos y sus proyectos de una vida en los Estados Unidos (Herra, 2008), se requería coaccionar al pueblo de la zona de Los Santos para que identificara el problema construido desde universidad y por la universidad, mecanismos propios de la racionalidad moderna, lo que nos ubicaba en el campo de la investigación tradicional y no de la investigación acción participativa (IAP), la cual se constituye 
en el horizonte de sentido que conduce el proyecto por el que fuimos invitados a aportar conocimientos y aprender saberes con las comunidades guanacastecas.

En términos metodológicos, la IAP permite desarrollar procesos investigativos en los cuales la universidad, el investigador o investigadora y la escuela aprenden no solo del proceso investigativo, sino sobre las diversas agendas locales, cómo estas están compuestas, cómo se problematiza, cómo se construyen, cómo se confrontan, con la intención de transformar las relaciones de opresión en las que sobreviven, resisten y se confrontan los pueblos ${ }^{1}$ del Tercer Mundo ${ }^{2}$.

El vacío al que en inicio el equipo del proyecto se enfrentó tuvo que ver con que la información investigativa en términos cuantitativos nos exigía volver los ojos hacia la zona de Los Santos. Sin embargo, allí debíamos jugar un papel de "investigación tradicional", en la cual quien investiga define la(s) agenda(s) a investigar, las impone a las poblaciones con las que trabaja, les señala el problema e incluso el camino que deben tomar para resolverlo. Estábamos, como equipo investigativo, ante un problema que era necesario enfrentar. Mientras esto sucedía en el campo investigativo, el proyecto "Alfabetización crítica en la cultura escolar" fue invitado a participar en una reunión impulsada por la Comunidad de Corral de Piedra en Nicoya, Guanacaste, el sábado 18 de febrero del año 2011. Esta reunión tenía como propósito informar a la comunidad de Nicoya sobre los proyectos extractivos, en términos ambientales, que se estaban desarrollando en la zona, y el interés, por parte de la empresa constructora Holsim, de nacionalidad suiza, por explotar los recursos ambientales ${ }^{3}$ de las comunidades de Roblar y Corral de Piedra, lo que hubiese incrementado la sedimentación del río Tempisque, del humedal Corral de Piedra y la contaminación del Parque Nacional Palo Verde, en la provincia de Guanacaste (Era Verde, 2012; Era Verde, 2012a; Herra, 2012a).

$1 \quad$ Al establecer su lectura de la realidad social de la época, Marx hizo una diferencia fundamental entre Gesellschaft (sociedad) y Gemeinschaft (comunidad). Marx llamó sociedad a "la reunión o asociación de individuos (individuales sin intereses comunes sino sólo individuales y por eso egoístas) en el mundo moderno..." la cual está mediada a través de contratos formales (Bautista, 2010, pp. 83-84), mientras que lo comunitario, mediado por articulaciones populares, tiene como horizonte de sentido la producción y reproducción de la vida. De esta forma, lo popular se relaciona con el conjunto de prácticas, relaciones y significados comunitarios que presuponen la vida y no al Ser contenido en el proyecto de la modernidad

Parto de la noción de Tercer Mundo siguiendo la línea de discusión propuesta por Frantz Fanon, en la cual la distancia que hay entre uno y otro mundo es un relación dialéctica de dependencia estructurada sobre la raza, como línea divisoria de lo humano, en la cual el colonialismo se impone sobre los pueblos "bárbaros" con el objetivo de llevarlos hacia una condición humana a través del cristianismo (tal como lo propusiera de las Casas en el famoso juicio de Valladolid entre este y Gines de Sepúlveda). Tal como lo deja en evidencia la obra de Henrique Dussel, previo a la conquista de América, Europa es una cultura marginal y periférica del Imperio Otomano (Dussel, 2011), por lo que el mismo Fanon (1961) señala con firmeza “Europa es, literalmente, la creación del Tercer Mundo" (Fanon, 1961, p. 94).

La diferencia fundamental que opera entre las nociones de recurso natural o naturaleza tienen que ver con el tipo de relaciones, interrelaciones, prácticas y significados que se establecen entre los seres humanos y el cosmos, del cual nuestro planeta es parte. En este sentido, la noción de recurso natural implica nombrar, comprender y relacionarse con el cosmos como si fuese un objeto a disposición del dominio occidental que puede controlarse y manipularse a su antojo. Este procedimiento se establece en un tipo de relación sujeto-objeto, del cual el calentamiento global es una manifestación estética de los efectos del tipo de racionalidad contenida en la modernidad. Por otro lado, la noción de naturaleza tiene que ver con un tipo de relación sujeto-sujeto, en la cual la naturaleza es identificada como una actriz clave sin la cual la vida no es posible. En el tipo de relaciones, interrelaciones, prácticas y significados que lo comunitario establece con su entorno, la naturaleza es identificada como el principio y fundamento de la vida, por lo cual se le debe respeto, cariño y protección como la madre que es. 
Esta actividad contó con la participación de diversas organizaciones sociales, institucionales y no institucionales, de la provincia de Guanacaste. La reunión tenía como propósito hacer una caminata al humedal de Corral de Piedra, en época seca, con la intención de observar el espacio físico, las diversas especies de aves acuáticas, animales y comunidades que iban a ser afectadas con el proyecto de extracción minera que intenta desarrollar Holsim en el Cerro Corral de Piedra, ubicado en esta comunidad. Una vez que esta caminata se realizó, se procedió a tener una discusión ampliada que intentaba problematizar lo que ahí estaba sucediendo. Esta discusión permitió conformar el Comité Ambiental Jabirú, conformado por las Asociaciones de Desarrollo de Pochote, Corral de Piedra, Líderes Comunales de la Comunidad Indígena de Matambuguito y el Comité Ambiental el Tucán, de barrio San Martín de Nicoya. Estas organizaciones están conformadas principalmente por mujeres, pero existe participación de hombres y jóvenes, sin distinción de sexo, que asumieron un compromiso con su realidad social inmediata.

Una vez de regreso al Campus Omar Dengo, tuvimos la necesidad de establecer discusiones profundas a lo interno del equipo de investigación que nos permitieran tomar decisiones inteligentes en el marco de la propuesta metodológica que estábamos ejecutando. Lo anterior se plantea debido a la alta dosis de emotividad que brotó en el campo durante la reunión convocada por la comunidad de Corral de Piedra de Nicoya.

De lo que se trataba era de tomar una decisión honesta, responsable y académicamente sustentada que nos permitiera construir desde las agendas sociales y con estas, que habían sido problematizadas, construidas y enfrentadas desde las distintas comunidades guanacastecas, pero con el riesgo de no ser un espacio con necesidades educativas significativas; o, por el otro lado, trabajar con la comunidad con mayores carencias educativas, en términos de inclusión en el sistema educativo formal, pero con el riesgo de que nuestro equipo investigativo asumiera posiciones que no nos corresponden, aun desde la academia.

Antes de tomar ninguna decisión respecto del viraje de la zona de estudio, necesitábamos contar con información confiable respecto del comportamiento del fenómeno educativo, para lo cual fue necesario construir una serie de tablas estadísticas, con base en la última información suministrada por el Centro de Población (2011), disponible en la base de datos del Centro Centroamericano de Población de la Universidad de Costa Rica4.

De esta forma, la discusión/reflexión respecto de la delimitación espacial y del fenómeno que tratábamos de entender fue llevando al equipo a prestar mayor atención a diferenciar las prácticas sociales, que se configuran o se forjan alrededor de la dinámica educativa formal/institu-

$4 \quad$ Esta información estadística permitió construir una reflexión académica que fue expuesta en una ponencia presentada en el Primer Seminario de Pedagogía e Investigación Educativa durante el mes de noviembre del 2012, que llevó por título "Exclusión social como práctica pedagógica en la economía mundo capitalista" y que ha sido publicado por la revista "Ensayos Pedagógicos" de la Universidad Nacional. 
cional, de las prácticas comunitarias, cuyo horizonte de sentido tiene que ver con la producción y reproducción de la vida, lo cual fue posible de realizar en torno a las discusiones compartidas a lo interno del equipo de investigación con apoyo de bibliografía especializada. En este transcurrir, el concepto o categoría de verticalidad fue estando cada vez más presente, lo que dejó en evidencia que el tipo de racionalidad contenida en la modernidad era un primer obstáculo que debíamos vencer para acercarnos a un fenómeno que, además de estar vivo, se dinamiza en nuestra realidad en dos lenguajes distintos cuyas prácticas y manifestaciones son igualmente distintas y que tienen que ver con el sincretismo con que se expresa la histórica confrontación entre adaptación y resistencia a la modernidad: lo societal ${ }^{5}$ y lo comunitario ${ }^{6}$.

A partir de lo anterior, se hace evidente que la lectura moderno/colonial ${ }^{7}$, desde donde se piensa societalmente lo educativo, habla en términos de verdad/falsedad, absolutos/relativos, cuantitativos/cualitativos, etc., porque el dominio y el control son el fundamento del formalismo con que opera la racionalidad moderna (Bautista, 2010). Lo anterior cobra materialidad en el fenómeno educativo a partir del orden moderno presente en él, principalmente porque la confrontación que se da por ser incluidos y dejar de ser excluidos, en el caso costarricense, se expresa en torno a un $50 \%$ de la población que es el porcentaje nacional que cuenta con educación secundaria completa (Programa Estado de la Nación, 2008).

La estrecha relación que tiene el acceso a la educación formal costarricense con la incidencia en la pobreza ${ }^{8}$ permite pensar que la exclusión educativa es parte de un fenómeno histórico que ha circunscrito las relaciones humanas en el campo de lo societal, obviando con ello las relaciones,

$5 \quad$ La relación de dominio que funge como motor de las relaciones sociales estructuradas en la modernidad son del tipo sujeto-objeto, en la que el sujeto impone al objeto una explicación determinándolo. Este tipo de proceder responde al tipo de preguntas planteadas por los filósofos griegos en tiempo en que Grecia era una pequeña colonia egipcia asediada constantemente por sus vecinos y retomada por la Europa latino-germánica (lo que da fundamento al nombre con que se conoce la posibilidad del renacer con que la Europa latino-germánica llama al periodo comprendido entre 1430-1440 mediados del siglo XVI) gracias al amor por la sabiduría con que los teólogos y filósofos árabes volvieron su vista sobre la filosofía griega desde el siglo VII de nuestra era.

Las formas de relacionamiento comunitaria, articuladas en torno a la producción y reproducción de la vida, se dinamizan a través de una interacción sujeto-sujeto. En ella quien construye una lectura construye muchas lecturas de su realidad y de su entorno porque, entre otras particularidades, la naturaleza, que es la vida misma, es un sujeto que debe ser reconocido y valorado como única posibilidad de garantizar la reproducción de la vida. De esta forma, la comunidad de Corral de Piedra defendió y defiende su cerro porque él es parte integral de ella.

El proyecto sexista/racista/clasista que da impulso a la modernidad no podría haber logrado organizar el mundo alrededor suyo sino se hubiese dotado de las condiciones materiales que le permitieran ser el centro del sistema-mundo. Esa base material que le ha permitido a Europa ser un continente, por primera vez en la historia, ha sido posible gracias a la estructuración de un orden étnico complejo que de manera jerárquica permite la reproducción de la modernidad. Señala, de manera crítica, el filósofo Enrique Dussel que la modernidad y la colonialidad son una sola cosa indisoluble. Según este autor, sin la colonialidad la Europa latino-germánica hubiese continuado siendo una cultura marginal y periférica del Imperio Otomano (Dussel, 2011).

Según datos del segundo informe sobre desarrollo humano en Centroamérica y Panamá, presentado por el Proyecto de Naciones Unidas para el Desarrollo, para quienes "...tienen primaria completa (6 grados) la incidencia es menor del $40 \%$, y para los que han culminado la educación media o secundaria (entre 11 y 12 años, dependiendo de los países), la incidencia es apenas superior al 10\%" (PNUD, 2003: 66). Según señala el mismo informe, para quienes tienen educación superior la incidencia de la pobreza es muy inferior en comparación con los que no la tienen. Asimismo, la incidencia se reduce 4 puntos porcentuales por cada año de estudio que los sujetos tengan hasta los 12 años. 
interrelaciones, prácticas y significados que lo comunitario le ha dado a lo educativo. De esta forma cobra sentido la lectura crítica hecha por Fanon (2012) respecto de la nebulosa línea que separa la infraestructura de la superestructura en los espacios colonizados, al señalar que "en las colonias, la infraestructura es igualmente una superestructura. La causa es consecuencia: se es rico porque se es blanco, se es blanco porque se es rico" (Fanon, 2012, p. 34). En nuestras realidades y prácticas comunitarias, inferiorizadas por las prácticas societales impuestas en la modernidad, se podría señalar que se estudia porque se tienen recursos económicos y se tienen recursos económicos porque se estudia. Sin embargo, lo educativo, "la alfabetización, y por ende toda la tarea de educar, sólo será auténticamente humanista en la medida en que procure la integración del individuo a su realidad nacional, en la medida en que le pierda miedo a la libertad, en la medida en que pueda crear en el educando un proceso de recreación, de búsqueda, de independencia y, a la vez, de solidaridad" (Freire, 1975, p. 14), lo que tiene que ver con una práctica de lo educativo articulada estrechamente a la vida y de hacerla posible.

La posibilidad de aprendizaje que este equipo de investigación pudo haberse perdido al optar por una propuesta metodológica formal, tradicional, moderna, de control y dominio fue precisamente lo que estaba en la balanza al tomar decisiones en cuyo horizonte de sentido estuviese en la transformación social o popular. De esta forma, aun cuando problematizamos lo educativo en términos formales al inicio de esta fase del proyecto, lo comunitario/popular tuvo un acento mayúsculo por la claridad política con que se defiende la vida por parte de los pueblos en movimiento (De Sousa Santos) de América Latina.

\section{Jerarquías y dinámicas verticales de poder en el espacio de lo local como condición para la reproducción del orden moderno/colonial}

Una vez tomada la decisión de acompañar a la comunidad de Corral de Piedra en su lucha comunitaria, a través del desarrollo de un agenda impulsada por el Comité Ambiental Jabirú mediante actividades educativas y de alfabetización política, fue necesario establecer un viraje en la bibliografía para contar con categorías de análisis y conceptos para comprender lo que estaba sucediendo. Este giro teórico fue tornando en algo más complejo para formar parte de una discusión, impulsada desde el Tercer Mundo, que intenta pensar más allá que la modernidad, como lo reflejan la obra de Bautista, Dussel, Grosfoguel, Tuhiwai, Putnam, Quijano, entre otras y otros.

Lo primero sobre lo que se fue teniendo mayor claridad fue que las jerarquías de poder que se dinamizan alrededor de la institucionalidad de lo educativo tienden a privilegiar el orden social existente en la ciudad sobre lo comunitario rural. De esta forma, los "avances de la humanidad" o los derechos de la humanidad llegan tarde a los espacios rurales como manifestación del desplazamiento de un orden centrado en el campo, propio del orden latino, por una nueva forma de organización social y económica centrada en la ciudad, para lo cual fue necesario producir un nuevo tipo de teología, que en realidad se trataba de una disputa ideológica en- 
tre el antiguo y nuevo orden, que permitiera dejar de concebir el trabajo como una maldición principalmente porque las ciudades europeas están atestadas de miserables provenientes del campo que no tenían más que su fuerza de trabajo (Bautista, 2010).

Cuando la imposición colonial occidental en la Pacha-Mama, el Abya-yala, el nuevo Mundo, la Nueva España o lo que hoy es conocido como América Latina cumple 522 años de vigencia, se hace evidente que los elementos anteriormente señalados se expresan de forma recrudecida tal que "ahora en la modernidad, la racionalidad de la ciudad, empobreció la vida campesina, que pareciera que la única forma de vida posible fuese la de la ciudad y no así la del campo, sino sólo en la ciudad, y la política que impulsa en consecuencia es la de "ciudadanizar" toda forma de vida, porque cree ingenuamente que la única forma de ser humano, es la de ser 'ciudadano', o sea habitante de la ciudad" (Bautista, 2010, p. 238). De esta forma, la reproducción de comportamientos diferenciados en torno al acceso y permanencia en el sistema educativo formal tiende a favorecer a jóvenes de zonas urbanas sobre aquellos o aquellas procedentes de zonas rurales, tal como muestran los distintos estudios realizados por el Programa Estado de la Nación; los tres informes del Estado de la Educación; así como las Encuestas de Intereses y Propósitos Múltiples del Instituto Nacional de Estadística y Censos. Esto permite identificar el privilegio institucional a las prácticas y relaciones sociales, desarrolladas principalmente en la ciudad, sobre las relaciones o prácticas comunitarias, que aun cuando no tiene única presencia y manifestación en el campo tienen a este como espacio simbólico donde los pueblos o comunidades pueden producir y reproducir la vida al margen del aparataje de control occidental.

Un elemento que el equipo de investigación tuvo que reflexionar con seriedad estaba relacionado con la comprensión amplia del fenómeno educativo. Lo primero que identificamos, a lo largo del proyecto, fue que los orígenes de la institucionalidad de lo educativo tuvo y sigue teniendo relación con la constitución de un orden jerárquico que fomenta, valida, legitima y reproduce la desigualdad del aparataje institucional contenido en el sistema-mundo moderno. El nacimiento de la institución educativa moderna, ideada y reproducida en Occidente e impuesta en el sistema-mundo moderno, como única posibilidad de lo educativo, surgió ante la urgencia de acelerar el tránsito de la Europa antigua ${ }^{9}$ hacia la Europa moderna, la cual tenía la misión de desplazar los roles del padre y la madre a lo largo de su proceso formativo. La intención de lo anterior era garantizar que ambos no interfirieran en los nuevos valores y pre-juicios con los que la modernidad imponía un nuevo tipo de subjetividad, no es casualidad que son los internados la estructura pedagógica en los que se modela, organiza y reproduce un tipo de subjetividad en específico a través de una pedagogía de dominio (Bautista, 2010).

$9 \quad$ Centrada en el campo y la iglesia cristiana, las relaciones vasallo-feudales que prevalecieron a lo largo de la Edad Media (siglos IV-XIV), el secuestro, por parte de la Europa latino-germánica durante el siglo XIII, del tipo de racionalidad con la que había surgido la pregunta griega durante su época clásica (siglos IV-III a. C), dio las bases filosóficas y teológicas para el renacer de Europa. El nuevo tipo de racionalidad, caracterizada por la imposición del sujeto ante el objeto, le brindó a Europa las bases filosóficas y teológicas con las que justificó, posteriormente, la imposición militar en el Abya-Yala, la Pacha Mama, el Nuevo Mundo, la Nueva España y lo que hoy es conocido como América Latina. La Europa antigua, por lo tanto, es asociada con la Edad Media; y la dotación de un nuevo tipo de racionalidad de dominio es la Europa Moderna. 
Si bien es cierto, la dinámica moderna en la reproducción de la institucionalidad educativa costarricense no tuvo como principal escenario el internado, fue la institucionalidad de lo educativo, a partir de los procesos de construcción de los Estados nacionales centroamericanos (1821-1823), la condición que permitió la reproducción de la racionalidad de dominio contenida en la modernidad.

Lo anterior se logró, en el caso costarricense, a partir de la imposición de un orden vertical-jerárquico que reprodujo localmente los presupuestos contenidos en la modernidad ${ }^{10}$. Para ello, se organizó el poder político y económico en función de tres ejes estructurales: el mercado externo, la fuerza de trabajo y el monopolio de la tierra (Torres Rivas, 1974). Lo anterior urgió de la creación de mecanismos coercitivos "más sutiles o menos violentos para asegurar el ejercicio efectivo del poder. Ante lo cual [cursivas añadidas] adquirieron especial relevancia la educación, la formación de opinión pública, la participación política controlada, y la legitimación del propio Estado" (Samper, 1988, p. 162).

La estructuración y reproducción del orden vertical moderno/colonial en la dinámica educativa local, que han propiciado que los grupos oligarcas, desde el surgimiento del Estado-nación costarricense, hayan intentado hacerse de los bienes del Soberano ${ }^{11}$, se reproducen a partir de tres jerarquías en especíico:

a) La existencia de "una jerarquía lingüística entre las lenguas europeas y las no-europeas que hace primar la comunicación y la producción teórica y de conocimiento en los primeros, subalternizando los últimos como productores de folclor o cultura solamente pero no de conocimiento ni teoría" (Grosfoguel, 2006, p. 26). Este elemento particular peyoriza, inferioriza a las comunidades rurales costarricenses, principalmente porque sus dinámicas costeras, turísticas, agrícolas, para mencionar algunas de las actividades productivas, o la existencia de población originaria que se aferra a la defensa de sus tradiciones, de su historia y, en algunos casos, de su lengua, retan y confrontan la expansión del proyecto contenido en la modernidad. Estos retos o confrontaciones son identificados como frenos a la modernidad, y precisamente lo son, en tanto que el proyecto moderno es uno solo con el proyecto colonial (Baraona, 2009), por lo cual el freno a la expansión moderna es también un freno a la colonialidad.

En este sentido, las comunidades rurales guanacastecas de Matambuguito y Corral de Piedra de Nicoya tienen otras formas de comunicarse y herramientas colectivas para construcción del conocimiento y los saberes que les son pertinentes.

10 El "ser", que es el principio constitutivo de la racionalidad moderna, está pensado sobre la base de la"ley natural" que sostiene Aristóteles para justificar el por qué unos no tienen más capacidad que la de ser esclavos y que por eso lo son. Es ese "ser" el fundamento por el cual a lo largo del desarrollo de la modernidad se han recrudecido sus pilares constitutivos (sexismo/racismo/clasismo) así como el complejo orden étnico estructurado sobre ella.

11 Es importante hacer el señalamiento que previo a la Revolución Francesa el poder soberano recaía en las manos del Rey de España; pero que por el secuestro de Carlos IV de España por parte de Napoleón Bonaparte y el no reconocimiento de su hermano José Bonaparte como Rey de España, ocasionó que los pueblos de la Nueva España se confrontaran directamente con el poder colonial, ya fuese este francés o español, y se independizaran, al menos en apariencia administrativa, de su centro europeo. De esta forma, surge el pueblo como nuevo sujeto y actor político en América Latina cuya decisión y voluntad desde entonces es soberana. 
b) Reproducción de una jerarquía epistémica que posiciona, en un lugar de privilegio, los conocimientos y saberes occidentales sobre los no occidentales. Lo anterior no plantea, en ningún momento, que al hablarse de sistema universitario se excluye automáticamente los niveles de formación institucional inferiores. Lo que plantea es que la reproducción a escala planetaria del orden vertical del sistema-mundo no concibe otras formas de construir conocimiento, de reproducirlo, de socializarlo. Al respecto, urgió potenciar otras experiencias educativas que escaparan a la institucionalidad de lo educativo y que, entre otras cosas, propiciaran relaciones horizontales.

c) La identificación de jerarquía pedagógica donde se privilegian las pedagogías occidentales sobre las no occidentales lo que limita otras posibilidades, más no las elimina o desaparece en su totalidad. Este particular llamó la atención del equipo desde la primera invitación que se le hizo al proyecto para asistir a la comunidad de Corral de Piedra de Nicoya a inicios del año 2012.

Dinámicas de adaptación al orden contenido en la modernidad. La institucionalidad de la desigualdad educativa

La información disponible respecto del análisis científico de la dinámica educativa en Costa Rica deja en evidencia que el espacio geográfico es un determinante en la reproducción desigual de un orden vertical que se fomenta, valida, legitima y reproduce en la dinámica educativa institucional.

Un común denominador de la verticalidad con la que se expresa el sistema-mundo moderno en la dinámica educativa costarricense tiene que ver con la institucionalidad geográfica de la desigualdad con que se reproduce el fenómeno educativo en la actualidad, de forma tal que, en los contextos rurales, la desigualdad, la explotación, la exclusión, la pobreza son experiencias que tienden a maximizare (Centro Centroamericano de Población, 2011; Programa Estado de la Nación, 2008). Mientras que la población nacional ubicada entre los 13 y los 19 años de edad para el año 2012 estuvo constituida por un total de 560930 jóvenes, un total de 143113 jóvenes se encontraba fuera del sistema educativo formal, lo cual representó un $25,5 \%$ del total de la población de este grupo etáreo (Centro Centroamericano de Población, 2011). Sin embargo, al contrastar esta población por zona geográfica, se logra identificar que el comportamiento de la exclusión educativa respecto de la media nacional en las zonas urbanas tiende a ser menor que en las zonas rurales, de tal forma que mientras esta estuvo constituida por un total de 88709 jóvenes que representaron el $22,6 \%$ en las zonas urbanas, la exclusión educativa estuvo constituida por un total de 54404 jóvenes que representaron el 32,2\% de jóvenes en las zonas rurales (Centro Centroamericano de Población, 2011). El caso particular de Guanacaste es significativo, principalmente porque esta es la provincia que cuenta con mayor cantidad de personas con secundaria incompleta a nivel nacional, las cuales constituyen un total de 65779 personas quienes representan el 22\% del total de su provincia (Centro Centroamericano de Población, 2011). 
Lo anterior permite identificar que la reproducción práctica de un tipo de racionalidad fundamentada en relaciones de dominio, caracterizada por el éxito individual en esta fase ${ }^{12}$ particular de la modernidad, traslada la responsabilidad social de la permanencia o no en el sistema educativo formal al individuo de forma tal que las relaciones individuales ego-ístas impuestas en la modernidad se constituyen en el fundamento de la política educativa. El mensaje es claro: quien es explotado por la institucionalidad moderna está, de alguna forma, dentro de ella; por lo cual, lejos de reclamar, debería incluso agradecer. A lo que me refiero es a la profunda lección sexista/racista/clasista que tiene la institución pedagógica moderna: la exclusión es el fundamento sobre el que se construyen las relaciones sociales en la modernidad. De esta forma, la institucionalidad de lo educativo, que fomenta, reproduce y valida la exclusión social, se naturaliza como práctica social a través del discurso del mérito (Santos Guerra, 2000) el cual es interiorizado, interpersonalizado e institucionalizado (Fundación Puntos de Encuentro, 2001).

Atendiendo lo anterior, de lo que aquí se trató no fue de establecer un estudio de casos entre lo urbano y lo rural, cuyos resultados fueran cotejados; se intentó problematizar las experiencias educativas, pedagógicas e histórico-materiales a las cuales se enfrentan la juventud en comunidades rurales de Costa Rica, con atención particular en Nicoya, Guanacaste, lo que nos ha llevado a afirmar que lo que existe, en tanto práctica educativa, es la dinámica institucional de la desigualdad educativa.

Lo anterior permitió identificar cómo la defensa de la vida, que se traslada generación tras generación a través de prácticas comunitarias que se pueden identificar en la monta de toros, las rifas, los bailes populares, las fiestas patronales, las comidas típicas, el sincretismo teológico con el que se elevan las plegarias al cielo a través de vírgenes, santas y santos que hacen posible la reproducción de la vida comunitaria, se constituyen en la principal escuela para la vida. La posibilidad de tener acceso o no a lo institucional educativo es un tema distinto.

Dinámicas de resistencia al orden contenido en la modernidad. La comunidad educativa como praxis de la educación popular

Señalado con anterioridad, mientras que lo societal se impone a través de relaciones mediadas por contratos formales entre individuos egoístas, lo comunitario tiene que ver con las posibili-

Si bien la modernidad, desde una posicionalidad no occidentalizada, inicia en el momento mismo en que Colón declarara las tierras del Abya-yala o la Pacha Mama, propiedad de la Corona Española y la Iglesia Católica, esta ha atravesado por distintos momentos que van desde la paleo modernidad hasta la hipermodernidad (Baraona, 2011). Sin embargo, dado que esta discusión se enmarca en la imposición de lo colonial en la dinámica educativa y que esta tiene al lenguaje como su estructura principal, utilizaré los tres periodos de la colonialidad lingüística sugeridos por Calvet (2005): el precolonialismo, el cual está caracterizado por la teorización y construcción del yo a partir de la relación con el otro en la cual culmina imponiendo relaciones de superioridad donde había relaciones de diferencia. El colonialismo activo es el segundo momento identificado. En él la teoría lingüística desarrollada cobra materialidad práctica en el conjunto de relaciones sociales, que ahora son relaciones de dominio. Y por último, el neocolonialismo. En este"el problema lingüístico adquiere en ocasiones una importancia primordial. En -este- contexto la actitud lingüística es al mismo tiempo condición y máscara de la actitud política y económica" (Calvet, 2005, p. 51). Entendiendo aquí por problema lingüístico el conjunto de relaciones sociales que da vida práctica a la estructura lingüística como un todo, en la cual las relaciones sociales continúan su cruzada sobre la vida comunitaria. 
dades, prácticas, relaciones de producir y reproducir la vida (Baustista, 2010) y es precisamente lo que pasa en el contexto rural de Nicoya, Guanacaste. La comunidad de Corral de Piedra, organizada, en este caso, en torno a la defensa del Cerro que lleva su mismo nombre, se ve en la necesidad de desarrollar acciones colectivas que le permitan proteger el Cerro y la vida existente en él, para lo cual desarrolla una agenda de lucha, en clave popular ${ }^{13}$, que permitió conformar el Comité Ambiental Jabirú y garantizar, al menos por ahora, la vida de dicho Cerro.

La práctica educativa que tiene que ver con la construcción y transmisión de conocimientos y saberes adquiere, en el caso de la pedagogía popular, una relación de reconocimiento de la otra persona en tanto sujeto, del otro u otra como igual. No es casualidad que la comunidad de Corral de Piedra señale, de manera categórica, "defender el Cerro es defendernos a nosotros mismos porque el Cerro somos nosotros. Nosotros somos el Cerro" (Era Verde, 2012; Era Verde, 2012a). De esta forma, la creación del Comité Ambiental Jabirú tuvo como principal objetivo la defensa del Cerro Corral de Piedra y del Humedal, tipo RAMSAR, que lleva el mismo nombre. Este comité fue integrado, en inicio, por las comunidades de Corral de Piedra, Pochote, Barrio San Martín, el Comité Ambiental el Tucán y la comunidad indígena de Matambuguito de Nicoya. En este breve camino, organizaciones sociales y comunales de estas comunidades se integraron e impulsaron la defensa del cerro en cuestión, lo cual les permitió conocerse, acercarse, compartir experiencias y reconocerse intersubjetivamente en la lucha comunitaria a través de acciones de organización, educación y comunicación popular. Lo anterior permitió posicionar el tema a nivel nacional a través de la participación en cápsulas informativas en un canal de televisión nacional (Canal 15) y a través de distintos artículos de opinión en diarios costarricenses (Diario Digital El País.cr y La Prensa Libre).

La organización comunitaria y popular, durante el trayecto emprendido, permitió, al menos de momento, alcanzar el objetivo más significativo trazado por la comunidad desde el inicio de su grito desobediente y rebelde: obstaculizar el proyecto ideado por Holsim, al dejar en evidencia que ni la empresa española contratada por la Municipalidad de Nicoya para llevar a cabo el Plan Regulador ${ }^{14}$ (Gobierno de Costa Rica, 2011) ni ella misma podían dar cuenta de la necesidad o el impacto que ocasionaría degradar las zonas de recarga de mantos acuíferos, zonas de bajo impacto humano en el ambiente a ser, a partir de la fallida aprobación del Plan Regulador presentado por la empresa anteriormente señalada, como una zona industrial.

13 Mientras que el proletariado o el capitalista son los actores sociales llamados a enrumbar a la humanidad hacia un mundo sin clases sociales, en el primero de los casos, o hacia un mundo de riqueza y opulencia, en el segundo de ellos, el pueblo es el actor político que hace posible la producción y reproducción de la vida en lo comunitario. nómico y social de su territorio, elementos contemplados en el artículo 169 de la Constitución Política de Costa Rica, así como de Ley de Planificación Urbana 4240 de 1968. De no contarse con un Plan Regulador los municipios deberán acatar las disposiciones de los artículos 75 y 76 del Código Municipal, lo que inhibe a desarrolladores, empresarios y políticos de turno a desarrollar obras de infraestructura o actividades productivas que pongan en riesgo a la población y el ambiente. 
El plan para degradar estas comunidades ricas en bosques, pastizales, aves migratorias a zonas industriales se enfrentaba con la contradicción de que, en este espacio, la vida comercial, agrícola y económica tiene bajo impacto en el ambiente, principalmente porque sus prácticas comunitarias cuentan con un intenso arraigo en sus tradiciones, cultura y gastronomía.

\section{Balance provisional}

Si bien es cierto que el triunfo momentáneo es eso, una alegría temporal que debe ser gozada, reída, disfrutada, los elementos históricos que han marcado la realidad guanacasteca dejan claro que los intereses de la oligarquía local y el capitalismo planetario han puesto sus ojos en la extracción minera en Guanacaste (piedra caliza y oro ${ }^{15}$, principalmente). Lo anterior ha impuesto una importante tarea a la población de la provincia de Guanacaste: honrar la historia y la tierra que les ha permitido la posibilidad de la vida.

Si bien, en términos administrativos formales, lo guanacasteco se haya constituido socialmente como un proceso nacional paralelo a lo costarricense, lo simbólico, lo histórico, la rebeldía de quien rompe con el orden establecido y se siente orgulloso de mirar para atrás para tener claridad de quién es y de dónde viene, como bien lo expresara el cantautor guanacasteco Fidel Gamboa, con elementos comunitarios escindidos de lo costarricense aplastado por el proyecto del Estado nación. De esta forma, la música, el baile, la gastronomía, los toros, las montas y la gritería son elementos vivos de la resistencia comunitaria que se transmite generación tras generación a través de un legado educativo y pedagógico que mantiene aún viva la resistencia. La comunidad guanacasteca no enfrentó en el pasado o en la actualidad la lógica del dominio por casualidad. Lo enfrenta con la claridad de que no tienen mucho que ganar pero sí todo que perder: principalmente su identidad.

La identidad territorial del pueblo guanacasteco es, en la actualidad, uno de los principales focos de tensión social y política en el cual lo costarricense y lo guanacasteco se confrontan dialécticamente. Mientras que lo costarricense actuó y actúa en la lógica oligarca del poder, como continuación histórica del orden y del poder colonial, lo guanacasteco se aferra a la tierra, sus recursos y a su identidad histórica como un elemento que agita sus consciencias y que les impulsa a defender lo suyo, a defender quienes son, a defender su vida. Si no fuese así, las comunidades de Corralillo, Copal, Corral de Piedra, San Martín, Quebrada Honda y Matambuguito, para hacer acento en las comunidades nicoyanas que hacen uso de la organización como acto de reivindicación política y que conforman hoy el Comité Ambiental Jabirú ${ }^{16}$, no hubiesen asumido el reto de enfrentar, como en el pasado, el poder impuesto.

$15 \quad$ Hay que recordar que la idea de reabrir las minas de abangares ha vuelto al tapete de la discusión política impulsada por grupos de poder económico que, en alianzas internacionales, no tienen contemplación en contaminar a su madre, nuestra tierra, si ello le genera réditos en el corto plazo: ¿Qué pasará cuando se hayan llevado todo? ¿Será eso lo que estos grupos entienden como desarrollo?

16 Este es solo uno de los muchos comités ambientales y sociales que se encuentran organizados actualmente en la provincia de Guanacaste. El sentido de hacer acento en él reside en la posibilidad y potencial que desde esta plataforma podemos desarrollar en adelante, principalmente pensando en la necesidad de integrar la noción amplia de la comunidad educativa más allá de las fronteras institucionales que han cercado el saber en el ámbito del colegio. 
Así como el orden nacional se fue imponiendo como un requisito fundamental para garantizar el poder en manos de los distintos sectores oligarcas que se disputaron y disputan el control de los aparatos económicos, productivos, jurídicos y políticos, la pauperización de las condiciones de vida en las comunidades costeras (Limón, Guanacaste y Puntarenas) se impuso e impone como consecuencia de la subdivisión social del trabajo. Estas comunidades, articuladas al orden costarricense como sus apéndices territoriales, fueron pensadas como espacios que podrían ser administrados por el orden "metropolitano", permitieron la reproducción capitalista a través de la explotación de la fuerza de trabajo local así como de la explotación de la naturaleza, disminuida en la lógica moderna a recurso natural.

La lucha por la preservación del medio ambiente en la provincia de Guanacaste ha evidenciado que detrás de la voracidad con que se depredan los bosques, los mantos acuíferos, los humedales, los cerros, los ríos y las playas, con la avaricia que se eliminan ecosistemas completos y se borra la fauna local, están los mega-consorcios transnacionales del cemento, el turismo (sexual incluido) y el narcotráfico. Lo anterior deja claro que las luchas por la defensa del ambiente es, en primera instancia, un proceso de resistencia a la modernidad.

Ante este escenario, las comunidades guanacastecas se reivindican hoy como un solo sujeto colectivo, comunitario y popular en disposición de resistir el proyecto que les ha explotado, les ubica como personas sumisas, incapaces de tomar sus propias decisiones y enajenadas.

Para ello, la educación no solo es una herramienta, un arma de resistencia y confrontación: la educación, en este caso, es una aliada en la defensa de la vida.

\section{Referencias}

Acuña, A. (2015). El migrante tico. Amelia Rueda. Recuperado de: http://www.ameliarueda.com/especiales/ticosenusa/

Baraona, M. (2009). Reflejos de un espejo fracturado. Costa Rica: Editorial Universidad Nacional.

Baraona, M. (2011). Diez ensayos críticos. Costa Rica: Editorial Germinal.

Bautista, J. (2010). Crítica a la razón boliviana. Elementos para una crítica de la subjetividad del boliviano con conciencia colonial, moderna y latinoamericana (3 ${ }^{\text {era }}$ ed.). Bolivia: Rincón ediciones.

Calvet, J. (2005). Lingüística y colonialismo. Breve tratado de glotofagia. Argentina: Editorial Fondo de Cultura.

Centro Centroamericano de Población. (2011). Base de datos. Centro Centroamericano de Población de la Universidad de Costa Rica. Recuperado de http://www.ccp.ucr.ac.cr. 
Dussel, E. (2011). Filosofía de la liberación (1 ${ }^{\text {era }}$ ed.). México: Fondo de Cultura Económica.

Era Verde. (2012). ¿Se enterrará en sedimentos al humedal Corral de Piedra? (parte 1, reportaje) Era Verde. Recuperado de https://www.youtube.com/watch?v=vwNBG_J5N2o

Era Verde. (2012a). ¿Se enterrará en sedimentos al humedal Corral de Piedra? (parte 2, reportaje) Era Verde. Recuperado de https://www.youtube.com/watch?v=nQQy_kLxv0U

Fanon, F. (2012). Los condenados de la tierra (5 ${ }^{\text {ta }}$ Reimp.]. México: Fondo de Cultura Económica.

Freire, P. (1975). La educación como práctica de libertad. México: Editorial Siglo XXI. 1975.

Fundación Puntos de Encuentro (2001) Colección de materiales metodológicos para desaprender la discriminación y la violencia y fomentar el aprecio a la diversidad. Nicaragua: Fundación Puntos de Encuentro.

Galeano, E. (1971). Las venas abiertas de América Latina. México: Siglo XXI.

Gobierno de Costa Rica. (2011). Plan Regulador del Cantón de Nicoya. Ministerio de Hacienda, Unidad Ejecutora del Programa 1284 OC/CR de Regularización el Catastro y Registro. [Documento presentado, no aprobado]: Inypsa

Grosfoguel, R. (2006). La descolonización de la economía política y los estudios postcoloniales transmodernidad, pensamiento fronterizo y colonialidad global. Recuperado de http:// www.decolonialtranslation.com/espanol/transmodernidad-pensamiento-fronterizo-y-colonialidad-global.html.

Herra, E (2008) "Condiciones sociales que median el abandono del sistema educativo formal por parte de jóvenes entre los 12 y los 18 años de edad en el cantón de Tarrazú, 1993-2006". (Tesis inédita de licenciatura). Universidad Nacional, Heredia, Costa Rica.

Herra, E. (2012). Exclusión social como práctica pedagógica en la economía mundo capitalista. El caso del abandono del sistema educativo formal costarricense por jóvenes entre los 12 y los 18 años de edad (2000-2010). Revista Ensayos pedagógicos, 7(1), 173-196.

Herra, E. (2012a). Entrevistas a profundidad a miembros del Comité Ambiental Jabirú (Febrero-Mayo, 2012). Proyecto Alfabetización crítica en la cultura escolar: Sociedad y derechos humanos. Universidad Nacional, Heredia, Costa Rica. 
Mignolo, W. (2007). La idea de América Latina. La herida colonial y la opción decolonial. España: Editorial Gedisa.

PNUD (2003) Segundo Informe sobre Desarrollo Humano en Centroamérica y Panamá. San José, Costa Rica: Programa de Naciones Unidas para el Desarrollo.

Programa Estado de la Nación para el Desarrollo Sostenible. (2008). Programa Estado de la Nación 2008. San José, Costa Rica: Programa Estado de la Nación.

Quijano, A. (2000). Colonialidad del poder, eurocentrismo y América Latina. Recuperado de http://bibliotecavirtual.clacso.org.ar/ar/libros/lander/quijano.rtf

Samper, M. (1988). Fuerzas sociopolíticas y procesos electorales en Costa Rica, 1921-1936. Revista de Historia. Número especial, 157-222.

Santos, M (2000) La escuela que aprende. España: Ediciones Morata.

Torres Rivas, E. (Mayo-agosto, 1974). Poder nacional y sociedad dependiente: Las clases y el Estado en Centroamérica. Revista Estudios Sociales Centroamericanos, 3(8), 27-63. Confederación Universitaria Centroamericana. 